\title{
Linear attenuation coefficient measurement in polymer composite
}

\author{
Nesreen B. Al-Rawi \\ Department of Physics, College of Science, Baghdad University \\ E-mail: HYNH-4@yahoo.com
}

\begin{abstract}
Linear attenuation coefficient of polymer composite for beta particles and bremsstrahlung ray were investigated as a function of the absorber thickness and energy. The attenuation coefficient were obtained using $\mathrm{NaI}(\mathrm{Tl})$ energy selective scintillation counter with ${ }^{90} \mathrm{Sr} /{ }^{90} \mathrm{Y}$ beta source having an energy range from $0.1-1.1 \mathrm{MeV}$. The present results show the capability of this composite to absorber beta particles and bremsstrahlung ray that yield from it. That's mean it is useful to choice this composite for radiation shielding of beta ray with low thickness.
\end{abstract}

Key words

Attenuation, polymer, Beta particle.

\section{Article info.}

Received: May. 2014

Accepted: Jun. 2014

Published: Dec. 2014

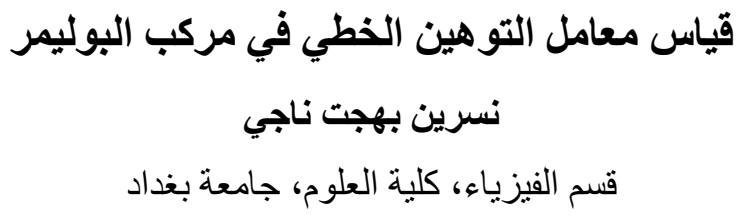

الخلاصة

تمت در اسة معامل التو هين الخطي لجسيمات بيتا وأنتعة الكبح في متر اكب ذو أساس بوليمري كدالة للطاقة وسمك المادة

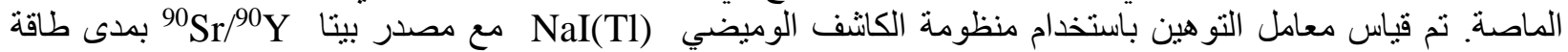

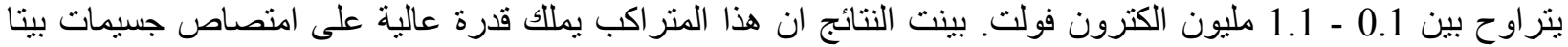
و اشعة الكبح الناتجة عنها. هذا يعني انه من المفيد اختيار هذا المتر اكب من اجل الحماية من اشعة بيتا وبسمك قليل.

\section{Introduction}

The study of interaction of radiation with the materials of common and industrial use, as well as biological and commercial importance has become major area of interest in the radiation field science. The attenuation coefficient is an important parameter characterizing the penetration and diffusion of rays in composite materials, and the accurate values linear attenuation coefficient of beta and bremsstrahlung rays for various media especially composite materials are useful for dosimetry, radiation shielding to choice the suitable type of material to adequately stop various forms of radiations, as well as for many nuclear physics experiments.[1]

The probability occurrence of any particular category of interaction, and hence the penetrating power of the several radiations, depends on:

1- The type of radiation and its energy.

2- The nature of the absorbing medium.

An extensive data on mass attenuation coefficients of gamma rays in compound and mixtures of dosimetric interest have been studied by Hubbel [2]. Other scientists such as Bradley et al.[3], Chaudhari and 
Girase [4] and Chaudhari and Rathod[5] measured mass attenuation coefficient for various absorber at different energies. In 1990 Dhaliwal et al.[6] studied the attenuation of bremsstrahlung from beta rays in $\mathrm{Al}, \mathrm{Cu}, \mathrm{Sn}$, and $\mathrm{Pb}$ materials.

Measurements on attenuation coefficients and range energy relation of beta particles for various absorbers at different energies have been reported by various workers as Rocca et al. [7] and Mahajan [8], also the attenuation coefficient of beta by composite were investigated by Pujol et al. [9] and Alzubadi [10].

In this work the absorption of beta particles and bremsstrahlung ray in different thickness of polymer composite are studied and measured the linear attenuation coefficient as a function of the energy and absorber thickness.

The attenuation of radiation expressed as Eq.(1):

$\mathrm{I}=\mathrm{I}_{\mathrm{o}} \exp (-\mu \mathrm{d})$

where $I_{0}$ is the number of particles counted during a certain time without any absorber, I is the number counted during the same time with a thickness $d$ of absorber between the radiation source and the detector, and $\mu$ is the linear absorption coefficient in $\mathrm{cm}^{-1}$.

This equation may be cast into the linear form, as Eq.(2):

$\mu=(1 / d) \log \left(I_{o} / I\right)$

\section{Materials and methods}

\section{Absorber materials}

The materials used in this work to prepare the composite samples as absorber with different thicknesses are; Epoxy Resin (EP), polyurethane (PU) and Lead powder with size of $200 \mu \mathrm{m}$.

\section{1-1Preparation of EP/PU blend}

To prepare the EP/PU Blend an exact amount of special hardener is added to the resin with weight ratio of hardener to resin $1: 3$. The content is mixed thoroughly by a fan type stirrer until the mixture becomes homogeneous.

A sufficient amount of isocyanate hardener is also added to resin (polyol) with weight ratio of hardener to resin 1:9. The content is also mixed thoroughly by a fan type stirrer before adding epoxy to the mixture.

The epoxy/ polyurethane blend are prepared with weight ratio of both polymers as $(20 \% \mathrm{EP}) /(80 \% \mathrm{PU})$. It is the best compatibility blend.

\section{1-2 Preparation the composite}

By the same manner of previous preparation using the ratio of blend (\%20PU)+(\%80EP), the lead/EP/PU composite are prepared with weight ratio of lead $70 \%$.

To get the required thickness, pour the mixture in templates with thickness ranging from 0.16 to $1.2 \mathrm{~cm}$, and the dimensions of $3 \times 2.5 \mathrm{~cm}$.

\section{Experimental setup}

The experimental arrangement with the electronic configuration is schematically shown in Fig.1. The assembly was placed in lead castle. Energy calibration was performed using a set of standard gamma sources.

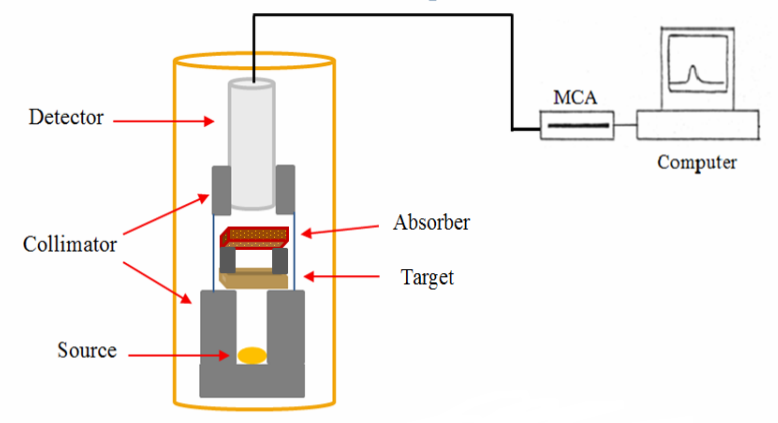

Fig.1: Schematic diagram of experimental setup. 
Measurements have been carried out using a collimated beam of pure beta source ${ }^{90} \mathrm{Sr} /{ }^{90} \mathrm{Y}$ with energy (0.546-2.274) $\mathrm{MeV}$. The beta-particles intensities behind the composite samples have been carried out by using sodium iodide crystal $\mathrm{NaI}(\mathrm{TI})$ scintillation detector. The incident and transmitted intensities were determined for fixed preset time at $600 \mathrm{sec}$ in each measurement.

Beta-particles intensities without and with different thickness have been measured. Measurements have been carried out with energy range $0.1-1.1 \mathrm{MeV}$, and the linear attenuation coefficient was calculated.

\section{Determination of beta-particles range}

The range of beta-particles, for energy range $0.01 \leq \mathrm{E} \leq 2.5 \mathrm{MeV}$ can be approximated by Baker and Katz[11 ]:

$\mathrm{R}\left(\mathrm{kg} \cdot \mathrm{m}^{-2}\right)=4.12 \mathrm{E}^{\mathrm{n}}(\mathrm{MeV})$ where $n=1.265-0.0954 \ln E_{\max }$

$\mathrm{E}_{\max }$ is the maximum beta-particles energy in $\mathrm{MeV}$ and, $\mathrm{R}$ is the range of beta-particles in $\mathrm{kg} \cdot \mathrm{m}^{-2}$.

Therefore a composite sheet of thickness $0.2 \mathrm{~cm}$, which is sufficient to stop all beta particles from ${ }^{90} \mathrm{Sr} /{ }^{90} \mathrm{Y}$ according to Eq.(3) was used as a beta stopper (target) to generate bremsstrahlung ray.

Bremsstrahlung ray count rate was recorded without and with different thicknesses of composite absorber and the linear attenuation coefficient was computed.

\section{Results and discussion}

The count rat as a function of energy in $\mathrm{MeV}$ without absorber material $(\mathrm{d}=0)$ and with absorber $(\mathrm{d}=0.16)$ was plotted as shown in Fig. 2 and the absorption spectra for beta particles in different thickness of absorber from 0.16 to $1.2 \mathrm{~cm}$ was shown in Fig.3. It is clear that the intensity of beta decrease with increase the thickness of the absorber.

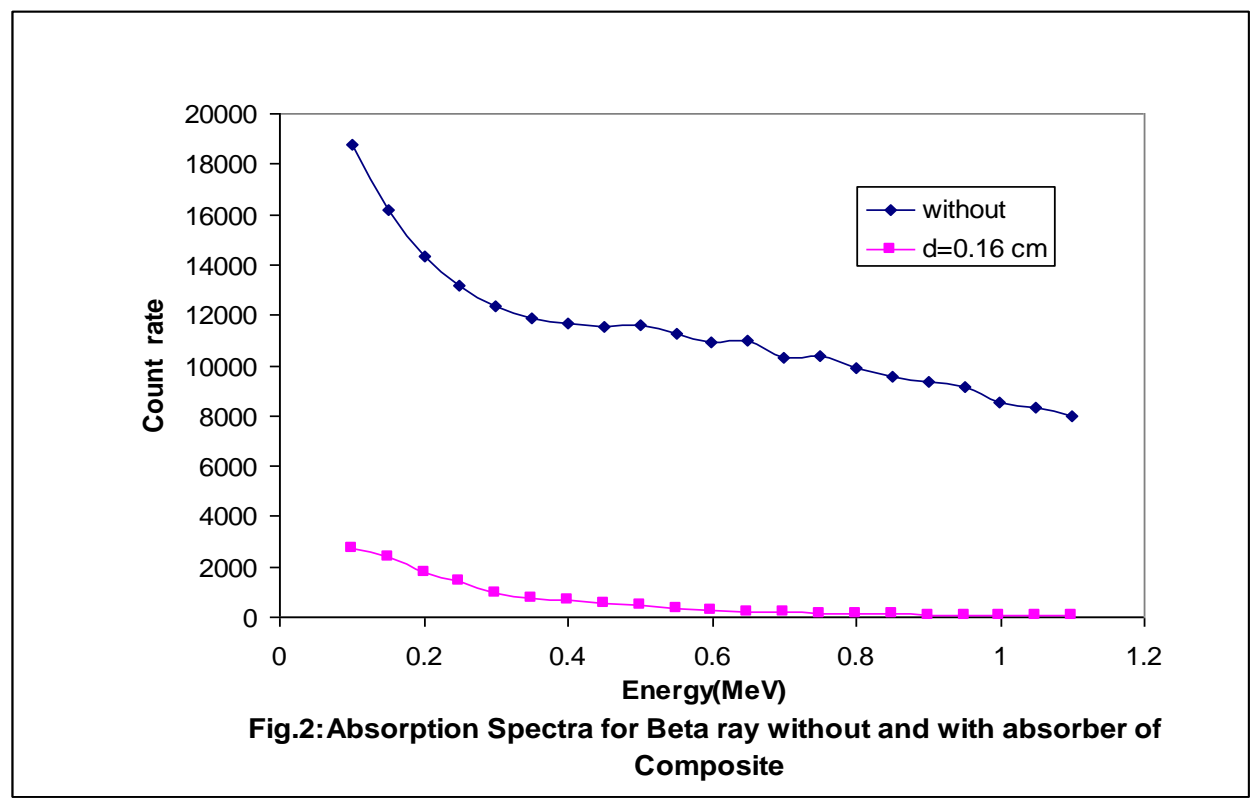




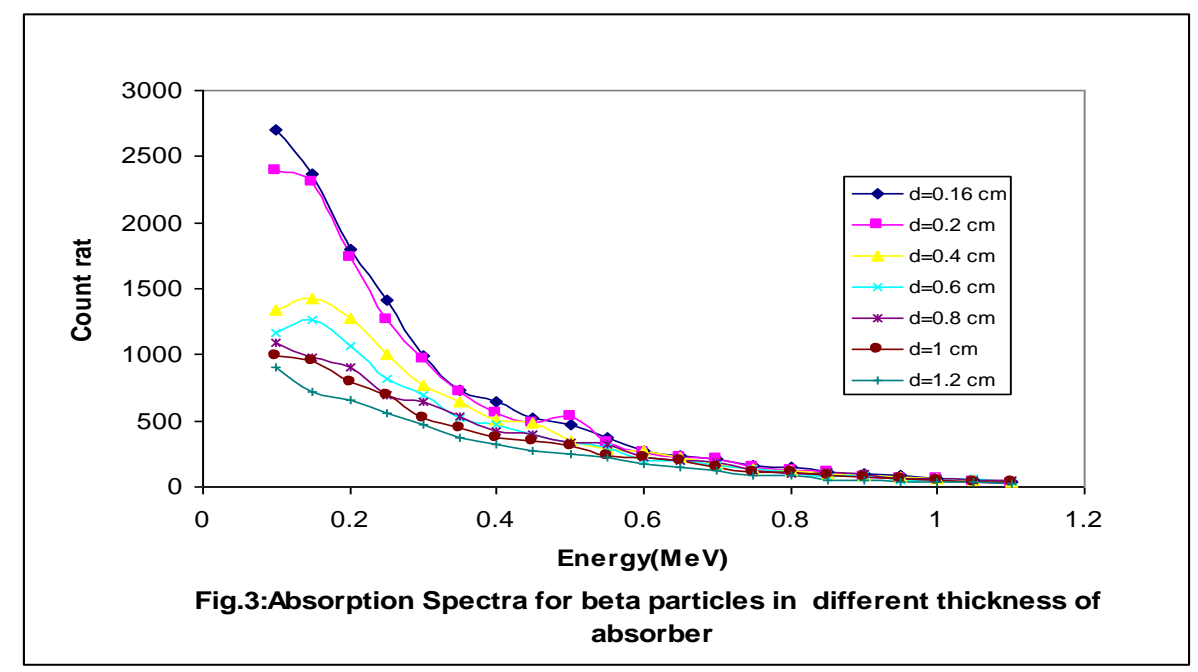

Linear attenuation coefficients of beta particle of energy range $0.1-1.1 \mathrm{MeV}$ for different thickness of polymer composite obtained from Eq. 2 are given in Table 1. It is shown that linear attenuation decrease with increase the thickness of absorber and increase with increase energy. These relations are shown in Figs. 4 and 5.

Table 1: Linear attenuation coefficients for different thickness of polymer composite $\left(\mathrm{cm}^{-1}\right)$.

\begin{tabular}{|c|c|c|c|c|c|c|c|}
\hline & \multicolumn{7}{|c|}{ Thickness } \\
\cline { 2 - 8 } & $\mathrm{d}=0.16 \mathrm{~cm}$ & $\mathrm{~d}=0.2 \mathrm{~cm}$ & $\mathrm{~d}=0.4 \mathrm{~cm}$ & $\mathrm{~d}=0.6 \mathrm{~cm}$ & $\mathrm{~d}=0.8 \mathrm{~cm}$ & $\mathrm{~d}=1 \mathrm{~cm}$ & $\mathrm{~d}=1.2 \mathrm{~cm}$ \\
\hline $\mathrm{E}(\mathrm{MeV})$ & $\mu_{1}$ & $\mu_{2}$ & $\mu_{3}$ & $\mu_{4}$ & $\mu_{5}$ & $\mu_{6}$ & $\mu_{7}$ \\
\hline 0.1 & 12.1065 & 10.2819 & 6.5959 & 4.6276 & 3.5537 & 2.9410 & 2.5229 \\
\hline 0.15 & 12.0283 & 9.7620 & 6.0813 & 4.2451 & 3.5030 & 2.8355 & 2.5925 \\
\hline 0.2 & 12.9686 & 10.5416 & 6.0403 & 4.3320 & 3.4484 & 2.8992 & 2.5635 \\
\hline 0.25 & 13.9594 & 11.7445 & 6.4380 & 4.6355 & 3.6806 & 2.9402 & 2.6325 \\
\hline 0.3 & 15.7865 & 12.7728 & 6.9306 & 4.7929 & 3.6935 & 3.1706 & 2.7177 \\
\hline 0.35 & 17.4071 & 13.9737 & 7.3025 & 5.2150 & 3.8850 & 3.2694 & 2.8761 \\
\hline 0.4 & 18.0444 & 15.2359 & 7.8350 & 5.3390 & 4.1351 & 3.4303 & 2.9977 \\
\hline 0.45 & 19.3886 & 15.8086 & 7.9559 & 5.6423 & 4.2285 & 3.5076 & 3.1174 \\
\hline 0.5 & 19.9060 & 16.4340 & 8.7690 & 5.8753 & 4.4289 & 3.6117 & 3.2126 \\
\hline 0.55 & 21.2791 & 17.4998 & 9.2175 & 6.0530 & 4.4507 & 3.8650 & 3.2718 \\
\hline 0.6 & 23.0822 & 18.7472 & 9.2420 & 6.7307 & 4.8683 & 3.8901 & 3.4560 \\
\hline 0.65 & 23.9709 & 19.5050 & 9.6745 & 6.6597 & 5.0456 & 4.0008 & 3.5906 \\
\hline 0.7 & 24.3263 & 19.6052 & 10.3002 & 6.9481 & 5.0432 & 4.2267 & 3.6797 \\
\hline 0.75 & 25.7714 & 21.0239 & 10.8597 & 7.2398 & 5.5068 & 4.5412 & 3.9516 \\
\hline 0.8 & 26.3248 & 21.8704 & 10.8775 & 7.5032 & 5.7341 & 4.5202 & 3.9005 \\
\hline 0.85 & 27.5152 & 22.1861 & 11.5006 & 7.6671 & 5.6030 & 4.7457 & 4.3285 \\
\hline 0.9 & 28.2907 & 23.9891 & 11.5496 & 7.8513 & 5.7612 & 4.8241 & 4.3748 \\
\hline 0.95 & 29.0206 & 24.5056 & 12.2163 & 8.5527 & 6.1828 & 5.0430 & 4.5475 \\
\hline 1.0 & 30.5617 & 25.1170 & 12.0731 & 8.3428 & 6.2353 & 5.1986 & 4.5778 \\
\hline 1.05 & 32.5086 & 27.0954 & 12.6025 & 8.3116 & 6.5017 & 5.5335 & 4.6112 \\
\hline 1.1 & 33.6072 & 28.1038 & 13.3112 & 9.2030 & 6.3703 & 5.4915 & 4.9136 \\
\hline
\end{tabular}



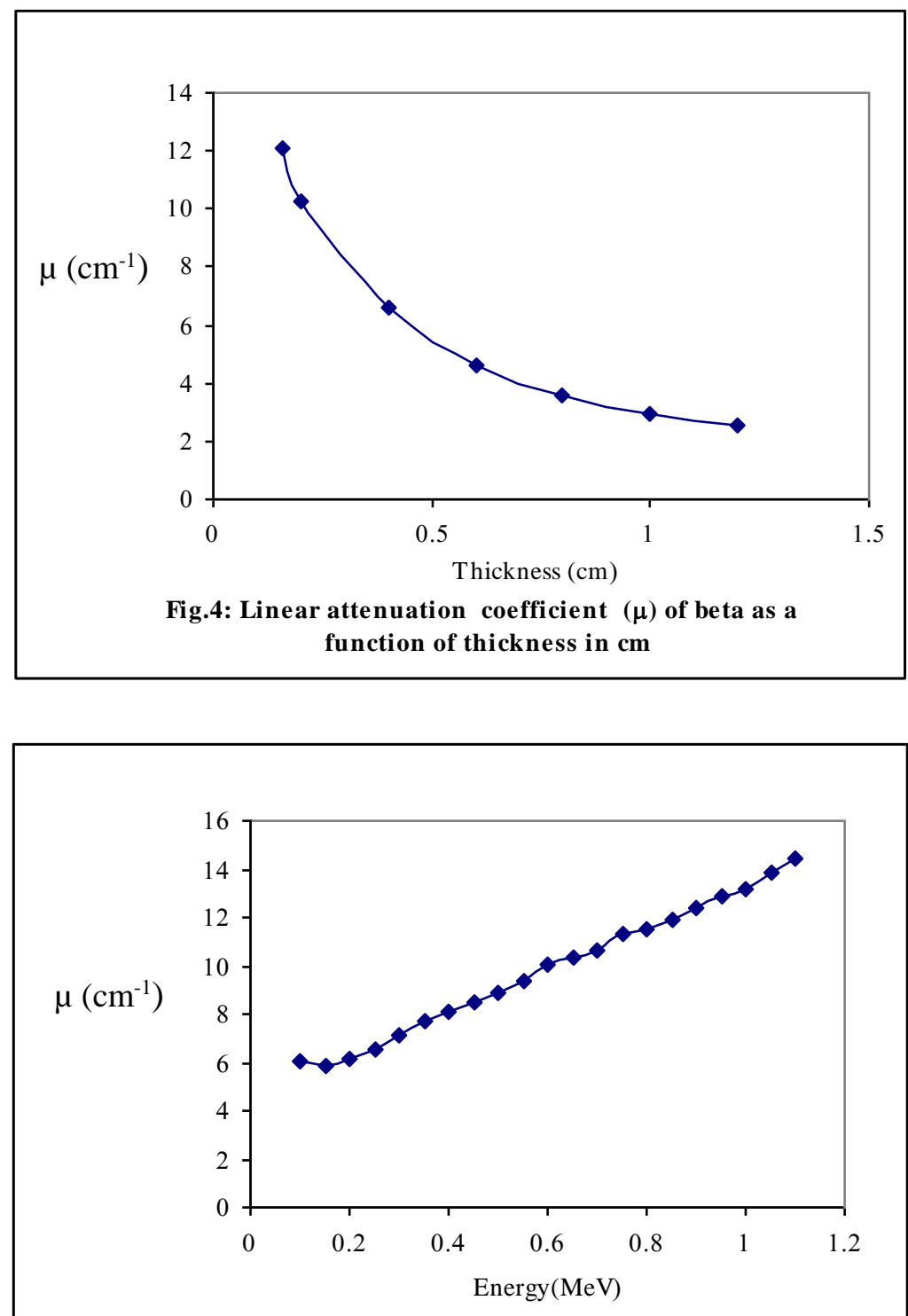

Fig.5: Linear attenuation coefficient $(\mu)$ of beta as function of energy in Me V

In Fig.6 the count rate as a function of energy in $\mathrm{MeV}$ without absorber material $(d=0)$ and with different thicknesses of absorber was plotted to obtain the absorption spectra for bremsstrahlung ray. It is found that the intensity of bremsstrahulng ray decrease with increase the thickness of the absorber that is clear in low energy regions.
Fig.7 shows the intensity (ln I) as a function of thickness of absorber. The slope of this graph gives the value of linear attenuation coefficient.

In the same way we obtain the linear attenuation coefficients for the range of energies from 0.1 to $1.1 \mathrm{MeV}$, and plotted in Fig.8. It is found that the linear attenuation coefficient decreases with increase energy. 

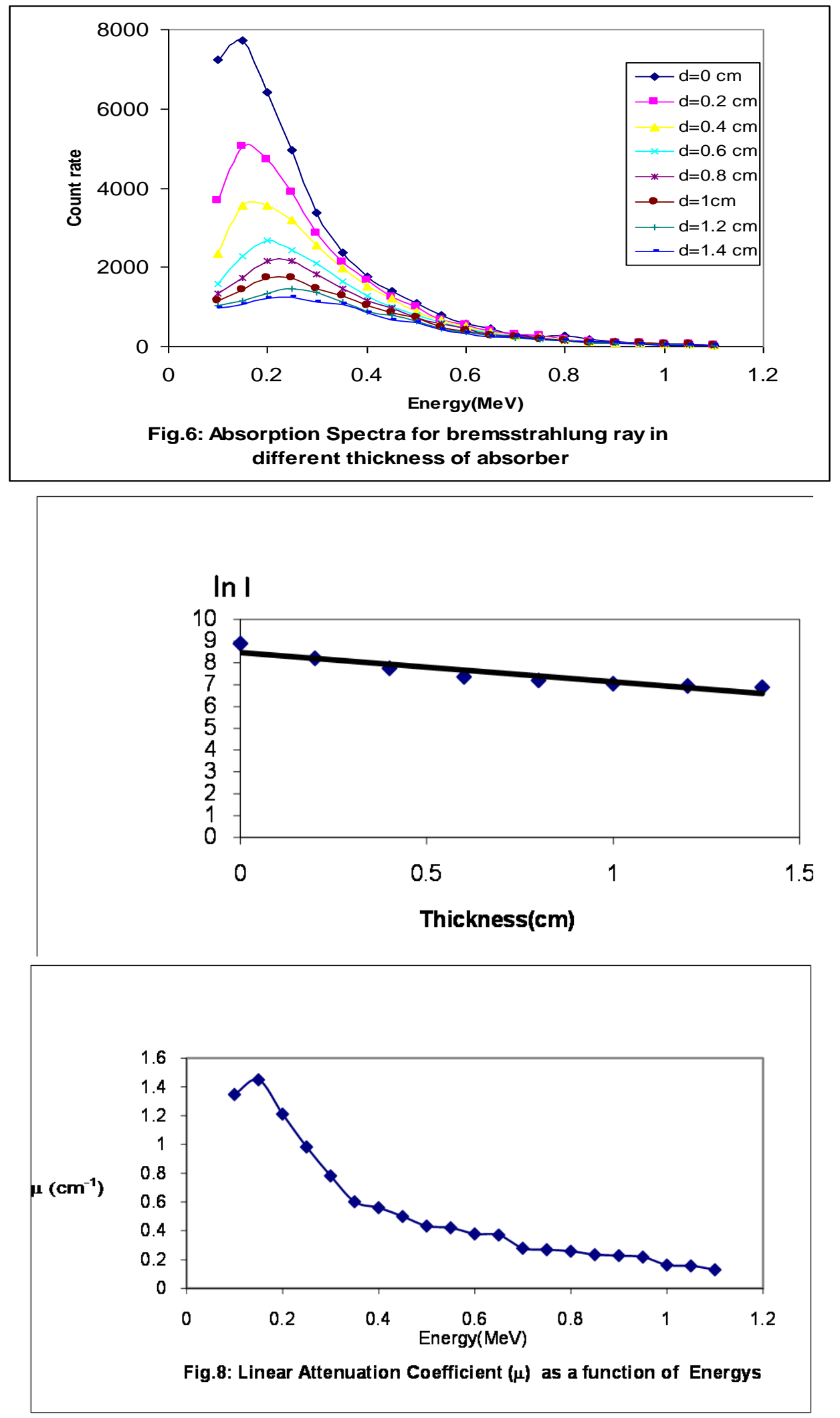


\section{Conclusions}

The attenuation of radiation can be achieved using a wide range of materials and understanding the basic principles involved in the physical interaction of radiation with matter that can help in the choice of shielding for a given application.

Therefore from the above results obtained that the lead/EP/PU polymer composite material is good absorber of beta and bremsstrahulng ray. It can use as a shielding for beta sources instead of shield with two materials first with low $\mathrm{Z}$ and second with high $Z$. Also this material can be used to make radiation protective clothing and aprons for the medical, scientific and nuclear industries.

\section{References}

[1]L. Chaudhari and D. Raje, Res. J. Chem. Sci. 2, 5 (2012) 17.
[2] J.H. Hubbell, Appli. Radiat. Isot. 33 (1982) 1269.

[3] D.D. Bradley, C.S. Chong, A. Shukri, A.A. Tajuddin and A.M. Ghose, Nucl. Instrum. Meth.Phys. Res. A280, (1989) 39.

[4] L. Chaudhari and S. B. Girase, Res. J. Recent Sci. 2, 3 (2013) 7.

[5] L.M. Chaudhari and S.Z. Rathod, J. Chem. Bio. Phy. Sci., C 3, 3 (2013) 2087.

[6] A. S. Dhaliwal, M. S. Power and Singh, Nucl. Sci.106 (1990) 452.

[7] Paola La Rocca and Francesco Riggi, Eur. J. Phys. 30 (2009) 1417.

[8] C. S. Mahajan, Science Research Reporter, 2, 2 (2012) 135.

[9]L. Pujol and J.A.Suarez-Navarro, Applied Radiation and Isotopes, 60 (2004) 693.

[10] Ali A. Alzubadi, Iraqi Journal of Physics, 8 (2010) 77.

[11] R. G. Baker, L. Katz, Nucleonics, 11 (1953) 14. 